\title{
UM ESTUDO SOBRE AS VARIÁVEIS QUE INFLUENCIAM NA EFICIÊNCIA DOS PREGÕES ELETRÔNI- COS COMO FERRAMENTA DAS COMPRAS PÚBLICAS
}

\section{A STUDY ON THE VARIABLES THAT INFLUENCE THE EFFICIENCY OF ELECTRONIC PREREQUI- SITES AS A TOOL FOR PUBLIC PURCHASES}

\section{RESUMO}

$†$ Renato José De Sena Gomes ${ }^{1}$

Este trabalho foi fruto de uma dissertação de mestrado em gestão pública e teve como foco o procedimento de compra estatal com a utilização de pregão eletrônico. Por meio de uma pesquisa quantitativa, buscou-se identificar variáveis que influenciam no cancelamento de itens na fase final do pregão. A revisão da literatura foi baseada em quatro temáticas: A licitação propriamente dita e o pregão eletrônico enquanto modalidade licitatória; As vantagens e desvantagens em utiliza-lo e a regressão logística. De caráter quantitativo, o estudo utilizou-se da regressão logística para analisar um grupo de 15 variáveis independentes em uma amostra de 550 observações de itens de consumo licitados por 10 universidades federais nordestinas. Concluiu-se que a demanda, o valor do produto e a relação entre a quantidade de itens no edital e o número de fornecedores, exercem forte e positiva influência sobre o resultado e que a utilização de Atas de registro de preços contribuem significativamente para o aumento da probabilidade de cancelamentos. Dentre as limitações do trabalho estão a não identificação de variáveis capazes de mensurar os efeitos do mercado e que avaliassem qualitativamente o instrumento convocatório. São sugestões para trabalhos futuros: Análise qualitativa do instrumento convocatório; Análise da correlação negativa da Ata de registro de preços sobre o resultado do Pregão; Até que ponto a metodologia de determinação do preço estimado é precisa.

Palavras-chave: Pregão eletrônico; Licitação; Regressão logística e Compras Públicas.

\section{ABSTRACT}

This work was the result of a master's thesis in Public Management and focused on the state purchase procedure with the use of electronic trading. By means of a quantitative research, we sought to identify variables that influence in cancellation of items in the final phase of trading session. The literature review was based on four themes: the bidding itself and the electronic trading while modality tender document; the advantages and disadvantages in using it and the logistic regression. A quantitative character, the study used of logistic regression to analyze a group of 15 independent variables in a sample of 550 observations of consumer items auctioned for 10 northeastern federal universities. It was concluded that the demand, the value of the product and the relationship between the quantity of items in the writing and the number of suppliers, have a strong and positive influence on the result and that the use of prices registration act significantly contribute to increased probability of cancellations. Among the limitations of work are not identification of variables capable of measuring the effects of the market and that assess qualitatively the convening instrument. These are suggestions for future work: qualitative analysis of the instrument of the notice; These are suggestions for future work: qualitative analysis of the instrument; analysis of a negative correlation of prices registration act on the result of the Trading Session; until that point the methodology for determining the estimated price is accurate.

Key words: Electronic bidding; bidding; logistic regression and public purchases

\footnotetext{
${ }^{1}$ Mestre em Gestão Pública, Especialista em Contabilidade e Controladoria Empresarial e Bacharel em Ciências Contábeis pela Universidade Federal de Pernambuco - UFPE. (In Memoriam)
} 


\section{INTRODUÇÃO}

Desde o início da década de 1980 a Administração Pública, em todo o mundo, tem sido modificada por um processo de reforma que tem por objetivo torná-la mais eficiente. O modelo burocrático, até então predominante e com foco no processo, vem sendo substituído em diversos países pelo modelo gerencial que diferente do seu antecessor é voltado à obtenção de resultados (PEREIRA, 2006).

A chamada Reforma Gerencial foi iniciada no primeiro governo de Governo de Fernando Henrique, nos anos de 1990. Um de seus objetivos foi estabelecer mecanismos que aumentassem, ao mesmo tempo, controle e eficiência na aplicação dos recursos públicos, demanda que não era atendida pelo estabelecido na Lei de 8.666/93. Foi com o intuito de dar maior agilidade ao procedimento de compra atendendo aos preceitos da reforma gerencial que o pregão foi introduzido dentre as modalidades licitatórias (FERNANDES, 2010).

A implementação do pregão teve reflexos positivos na redução dos preços pagos pelo Estado e no tempo para conclusão do procedimento licitatório (NIEBUHR, 2013). Em sua forma eletrônica, ele tornou-se a principal modalidade licitatória utilizada pela Administração Pública Federal no Brasil. Segundo Ministério do Planejamento Orçamento e Gestão - MPOG (2014), em 2013 foram realizados 36.956 procedimentos de licitação o que correspondeu a mais de $59 \%$ de tudo aquilo que foi gasto pelo Governo Federal com licitação naquele ano.

No entanto, o pregão não representou o fim da rigidez do procedimento licitatório no Brasil. Independente da modalidade selecionada, a licitação é, por forçada lei, um procedimento formal, onde uma série sequenciada de procedimentos deve ser rigorosamente obedecida (BRASIL, 1993). E onde a capacidade discricionária do gestor limita-se a fase anterior à publicação do edital (JUSTEN FILHO, 2002). Impõemse assim, dificuldades atividade de compra no setor público em função da formalidade rígida do procedimento, que na ótica de Segundo Antunes (2012), está relacionado com comprar aquilo que se demandou na quantidade e qualidade certas e com o fluxo de fornecimento adequado, de maneira a evitar excesso, escassez ou obsolescência de produtos em estoque.

Analisando Licitações realizadas por 10 Universidades Federais com cede em cidades nordestinas esta pesquisa identificou, entre os anos de 2009 e 2013 por meio do site de compras do Governo Federal, 7.324 pregões abertos para a aquisição de 243.822 produtos ou serviços. Deste total, 49.136 itens licitados foram cancelados na fase de aceitação do Pregão. Considerando apenas o ano de 2013 e somente itens classificáveis como de consumo, mais de um quinto do que foi licitado foi cancelado na fase final do processo.

Considerando que devido à complexidade do procedimento de licitação, o custo e o tempo gastos para sua realização, a Administração abre procedimentos de compra apenas quando a demanda é identificada ou identificável e nesse sentido o cancelamento do item por motivo diferente da extinção da demanda,

pode dentre outras coisas acarretar o desabastecimento dessas Universidades afetando seu funcionamento, o andamento de pesquisas científicas e a qualidade das aulas práticas em virtude da escassez de material. Diante do exposto buscou-se responder o seguinte questionamento: 
É possível identificar e estabelecer influência significativa de variáveis vinculadas ao processo de compra pública por meio de Pregão eletrônico, no sucesso ou fracasso de itens licitados de maneira a possibilitar ações preventivas, no caso de Universidades Federais com sede no nordeste?

\section{Revisão de Literatura}

\subsection{A licitação Conceito e Modalidades}

A legislação impõe aos gestores públicos uma série de limitações e obrigações necessárias à validade de uma licitação. A própria licitação é uma determinação da Constituição Federal de 1988. Estes limites têm por objetivo direcionar as ações da Administração Pública no sentido do atendimento dos interesses da sociedade e impedir a utilização do aparato estatal para favorecer aliados ou perseguir inimigos (NIEBUHR, 2013).

Mello (2012) corrobora este entendimento ao conceituar licitação como um procedimento prévio, rigorosamente estabelecido em lei e adotado pelo Poder Público quando este necessita contratar serviços ou adquirir bens, dentre outras situações. Ainda de acordo com ele, a licitação é um procedimento que possui duas fases fundamentais e um triplo objetivo.

As fases fundamentais do procedimento de licitação são a habilitação e o julgamento. Na primeira os interessados comprovam a capacidade de assumir as obrigações estabelecidas e na segunda é selecionada a proposta mais vantajosa para a Administração. E seus objetivos principais seriam assegurar a participação de todos os interessados, promover o desenvolvimento nacional sustentável e obter a proposta mais vantajosa (MELLO, 2012).

Em virtude da variedade de objetos o procedimento adotado para contratação não pode ser fixo. Conforme a complexidade e o volume de recursos utilizados para aquisição ou contratação daquilo que a Administração necessita a lei estabelece um conjunto de procedimentos a serem respeitados a serem seguidos objetivando a preservação do interesse público, conhecidos como modalidade de licitação (NIEBUHR, 2013). A variedade de modalidades, de acordo com Justen Filho (2002), é decorrência das exigências para que a Administração faça a melhor e mais eficiente contratação. Inicialmente, por meio da Lei de Licitações foram estabelecidas cinco modalidades de licitação (BRASIL, 1993): Concorrência, Tomada de preços, Convite, Concurso e Leilão. Cabe ao órgão licitante, com base nos critérios determinados pela lei e com base na análise do tipo do objeto licitado, no volume de recursos envolvido e na abrangência da licitação pretendida a definição da modalidade a ser utilizada.

$\mathrm{Na}$ maioria dos casos as modalidades devem ser selecionadas com base no valor total do contrato. Valores até cento e cinquenta mil reais podem ser contratados por meio de convite, aqueles entre cento e cinquenta mil e um milhão e meio de reais por meio de tomada de preços e valores superiores deverão ser contratos por meio da modalidade concorrência, podendo a Administração optar por modalidade mais complexa, na forma do que estabelece a lei (BRASIL, 1993). 
O primeiro acréscimo à lista de modalidades foi feito pela Medida Provisória $\mathrm{n}^{\mathrm{o}}$ 2.026/2000, que instituiu o Pregão e foi posteriormente confirmada pela Lei 10.520/2002. Diferente das demais modalidades licitatórias pode ser utilizado independente do valor. No entanto, sua utilização é restrita a "bens e serviços cujos padrões de desempenho e qualidade podem ser objetivamente definidos no edital, por meio de especificações usuais de mercado" (Brasil, 2002 artigo $1^{\circ}$ parágrafo único).

A sétima modalidade licitatória foi estabelecida inicialmente em caráter transitório pela Lei $\mathrm{n}^{\mathrm{o}}$ 12.462/2011, o Regime Diferenciado de Contratação (RDC) criado para suprir com mais agilidade as demandas por obras e serviços vinculados direta ou indiretamente aos Jogos Olímpicos, a Copa das Confederações da Federação Internacional de Futebol Associação (FIFA) e a Copa do Mundo de Futebol FIFA 2014 (DI PIETRO, 2013).

\subsection{O pregão e seus procedimentos}

A introdução do pregão está vinculada à necessidade do segundo governo de Fernando Henrique, 1999 - 2002, em aumentar o controle e a eficiência na aplicação de recursos públicos. O objetivo era superar dificuldades provocadas pela estrutura procedimental da Lei $n^{0} 8.666 / 93$ e gerar maior agilidade e eficiência ao procedimento de compra por meio da redução dos prazos, exclusão de ritos formais, flexibilização de regras e o aumento do poder discricionário do Gestor por meio da figura do pregoeiro (FERNANDES, 2010).

No que diz respeito à funcionalidade do Pregão, tanto o eletrônico (regulamentado pelo Decreto $\mathrm{n}^{\circ}$ $5.450 / 2005$ ) quanto ao presencial (regulamentado pelo Decreto $\mathrm{n}^{\mathrm{o}} 3.555 / 2000$ ), enquanto procedimento de compra proporcionaram diversas vantagens à Administração Pública. Niebuhr (2013) lista uma série dessas vantagens do Pregão em relação às demais modalidades. Segundo o autor, diferente das outras modalidades de licitação, não há um limite de valor estabelecido. Em segundo lugar, devido à inversão de fases, apenas o licitante possuidor do menor lance tem a documentação de habilitação analisada, o que torna o processo mais ágil. Além disso, a disputa por lances introduzida pelo Pregão gerou redução nos custos operacionais. Para Faria et al. (2010), a ampliação da concorrência também propiciou a redução dos preços pagos pela administração por bens e serviços.

O Pregão presencial como próprio nome indica ocorre em espaço físico na presença dos interessados, por meio de sessão pública onde serão apresentadas as propostas escritas e os lances verbais (BRASIL, 2000). O local e horário onde acontecerá a sessão pública são indicados no edital, bem como todos os procedimentos necessários desde a identificação dos interessados à abertura dos envelopes contendo as propostas são presididos pelo pregoeiro (BRASIL, 2010). 
Assim como a forma presencial, o pregão eletrônico é uma modalidade de licitação de tipo menor preço, distinguindo-se daquela pela utilização da internet para realização da disputa dos fornecedores durante a sessão pública (BRASIL, 2005). No caso de licitações promovidas por órgãos vinculados ao Sistema de Serviços Gerais (SISG), o procedimento ocorre com a utilização das ferramentas disponibilizadas pelo portal de compras do Governo Federal, o comprasgovernamentais.gov.br, e apenas por fornecedores previamente cadastrados no Sistema Unificado de Cadastramento de Fornecedores (SICAF) (BRASIL, 2005).

O Pregão foi introduzido objetivando, dentre outras coisas, dar maior celeridade ao procedimento de compra estatal. Isto não implicou, no entanto, na extinção da obrigatoriedade de seguir um rito burocrático hermético e sem a possibilidade de alteração por parte dos gestores. Mello (2012) e Di Pietro (2013) estabelecem a licitação e consequentemente o Pregão como um procedimento administrativo formal. Para Di Pietro (2013), o procedimento Administrativo pode ser entendido como um conjunto de atos que a Administração deve adotar como preparação de um Ato final. Nesse sentido, o edital e os procedimentos do Pregão como a habilitação e o recebimento das propostas são atos preparatórios do ato final, a assinatura do contrato.

A rigidez neste caso é consequência do fato que o conjunto de atos que compõem o procedimento, é estabelecido em uma ordem inalterável. Segundo Mello (2012), a realização do ato previsto como anterior é condição necessária e indispensável à realização daquele que lhe sucede. No caso do Pregão eletrônico, os 21 possíveis procedimentos indicados pelo TCU devem ser obrigatoriamente seguidos para que não se invalide todo o processo (BRASIL, 2010).

No que tange aos procedimentos a serem adotados no Pregão eletrônico e no presencial há diversas similaridades, inclusive repetições do estabelecido pelo Decreto $n^{\circ}$ 3.555/2000 e no Decreto $n^{\circ} 5.450 / 2005$ que regulamentam o Pregão presencial e o eletrônico respectivamente (DI PIETRO, 2013). Para efeito deste trabalho foi dado o enfoque aos procedimentos necessários ao Pregão em sua forma eletrônica, uma vez que este é seu objeto de estudo. No que tange aos procedimentos formais a serem seguidos pela Administração e pelos fornecedores para realização de uma licitação por meio de pregão, a legislação estabelece basicamente duas etapas ou fases. $\mathrm{Na}$ fase interna ou preparatória concentra-se a capacidade discricionária do gestor (JUSTEN FILHO, 2002). O Decreto n 5.450/2005 estabelece que na fase preparatória do Pregão eletrônico devam ser indicados:

a) A necessidade devidamente justificada do objeto da licitação, bem como, sua definição clara, contendo especificações objetivas e estritamente necessárias de modo a não limitar a competição;

b) As exigências de habilitação;

c) Os critérios de aceitação das propostas;

d) As sanções e cláusulas do contrato;

e) Os prazos para fornecimento.

É nesta fase que serão elaborados o termo de referência e o edital da licitação. Segundo Niebuhr (2013)2, é função do termo de referência descrever o objeto da contratação de maneira a fornecer aos interessados em contratar com a Administração as informações necessárias à formulação das propostas. A elaboração do termo de referência é de responsabilidade do órgão requisitante, nele o objeto deve ser especificado de maneira objetiva e de maneira a não restringir a competição. Também deverão constar o valor de mercado do produto ou serviço e a forma com que o objeto licitado será prestado ou fornecido (BRASIL, 2005). 
A fase externa, por sua vez, inicia-se com a Publicação ato convocatório, que no caso do pregão é o edital, e assemelha-se à etapa da modalidade concorrência, distinguindo-se desta pela inversão das fases de classificação e habilitação, compreendendo basicamente as fases do: "edital, julgamento e classificação, habilitação do licitante vencedor, adjudicação e homologação” (DI PIETRO, 2013, p.433). Mello (2012) afirma existir uma dependência da fase de sua antecessora o que torna impossível, do ponto de vista legal, sua modificação.

A fase externa da licitação é dada inicio com a publicação do edital. A abrangência do meio utilizado para divulgação deve ser maior quando maior for o volume financeiro envolvido conforme estabelecido no Decreto $n^{0} 5.450 / 2005$, partindo-se da publicação no Diário Oficial da União e da internet e somando-se jornais de publicação local, regional ou nacional conforme aumente o valor esperado do contrato.

Publicado o edital e não existindo pedidos de impugnação tem inicio a fase de lances. Inicialmente a empresas apresentam suas propostas que são ordenadas pelo sistema. Após isso, o pregoeiro indica as empresas classificadas têm início a fase de lances, neste momento o licitante não pode mais retirar as propostas realizadas. Podem ser ofertados lances sucessivos, desde que seja inferior sempre ao menor ofertado pelo licitante (BRASIL, 2005). O uso da internet é, segundo Di Pietro (2013), a característica que diferencia as duas formas de Pregão e, para Faria et al. (2010), é em função deste uso que a Administração tem conseguido reduzir os preços dos produtos e serviços contratados por meio da ampliação da concorrência.

Sendo aceita a proposta do licitante detentor do menor lance, tem-se início a habilitação. A Lei de Licitações, que subsidia a Lei do Pregão, estabelece como um de seus objetivos a seleção da "proposta mais vantajosa" para celebração do contrato (BRASIL, 1993). E a Lei que regulamenta o Pregão, por sua vez, estabelece o preço como principal critério de seleção, no entanto, a análise deve considerar os prazos de execução ou entrega bem como as exigências técnicas e de qualidade existentes no edital (BRASIL, 2005). O Decreto $n^{\circ} 5.450 / 2005$ possibilita à Administração exigir do licitante que comprove sua Habilitação Jurídica, qualificação técnica e econômica financeira, regularidade fiscal e o cumprimento ao dispositivo constitucional que veda a contratação de menores de 18 anos para determinados de atividades laborativas quando (BRASIL, 2005). Para Mello (2012, p. 597) é na fase de habilitação que o licitante prova possuir "[...] a qualificação indispensável para que sua proposta seja aceita". No Pregão, parte da documentação necessária à habilitação é apresentada no SICAF e não se faz mais necessária sua apresentação (BRASIL, 2005).

\subsection{Vantagens e desvantagens da utilização do Pregão}

O Governo Federal estabeleceu o pregão, em sua forma eletrônica, como modalidade prioritária com o objetivo de garantir a compra mais econômica e eficiente (BRASIL, 2000). No entanto, sua percepção como ferramenta mais eficiente, no sentido de atender ao interesse público não é consenso entre os estudiosos da temática. 
Como dito anteriormente, a introdução tinha por objetivo principal reduzir o tempo necessário ao procedimento de compra. Nesse sentido, o legislador inverteu as fases estabelecidas nas Lei $n^{\circ} 8.666 / 15$ e limitou a interposição de recursos a um período pré-determinado. Para Fernandes (2010), a introdução do pregão conseguiu tornar o procedimento de compra mais ágil. No entanto, a autora ressalta que algumas das inovações introduzidas como a limitação de determinado prazo para imposição de recursos podem cercear o direito a ampla defesa.

Outra nítida vantagem da utilização do pregão foi a redução significativa do custo final daquilo que a Administração deseja contratar. De acordo com Faria, Ferreira e Santos (2010), a redução dos preços pagos pela Administração foi consequência da ampliação da concorrência entre os fornecedores com a introdução da etapa de lances. Esta capacidade de ampliar a concorrência foi maximizada pela forma eletrônica do pregão que permitiu a participação de fornecedores sem a necessidade da presença física dos mesmos nos órgãos licitantes. O efeito negativo desta ampliação da concorrência, segundo os autores, é a transferência de capital de regiões menos desenvolvidas para as mais desenvolvidas em função da menor capacidade de concorrência dos fornecedores locais, refletindo negativamente na economia local.

Já Alves, Silva e Fonseca (2008), em um contexto de necessidade de aplicação eficiente dos recursos públicos, examinaram a introdução de instrumentos de controle gerencial no ciclo de suprimento do setor publico possibilitado pelas TIC's. Com foco no site de compras do Governo, o trabalho buscou identificar os reflexos da utilização destes recursos no ciclo de suprimento da Administração Pública. De acordo com os autores, a introdução das TIC's gerou o aumento do número de fornecedores e a opção crescente pelo Pregão eletrônico no procedimento de compra. No entanto, a capacidade de controle da Administração é baixa e devido a isso focada em ações específicas no procedimento de compra. Destaca-se, no entanto, que os sistemas atuais possibilitam a avaliação dos resultados graças à disponibilização de dados estatísticos (ALVES, SILVA E FONSECA, 2008).

Teixeira, Penedo e Almeida (2012) analisaram a relação entre preço pago e a qualidade dos produtos adquiridos em licitações realizadas em conformidade com as Leis $n^{\circ}$ 8.666/93 e a Lei $n^{0} 10.520 / 02$. Para os autores, embora existam mecanismos legais que buscam garantir a qualidade dos serviços e produtos adquiridos por meio de licitações a atual estrutura legal focou-se excessivamente no valor, deixando para um segundo plano a qualidade, situação que se agravou com o Pregão.

Consideradas as vantagens e desvantagens da nova modalidade apresentadas neste tópico é possível identificar a necessidade de possíveis adequações ao procedimento via pregão. No entanto, comparado às modalidades disponíveis ele é provavelmente, ainda, a melhor opção.

\subsection{Regressão Logística - logit}

A grande disponibilidade de dados possibilitada pela tecnologia da informação e o desenvolvimento de softwares e hardwares específicos para realização de cálculos estatísticos disponibilizou inúmeras fontes de dados aos gestores, influenciando no processo decisório. 
Dessa maneira, o conhecimento e a capacidade de interpretação de cálculos estatísticos tornaram-se essenciais para gerenciar (LEVINE, BERENSON E STEPHAN, 2000). No entanto, quando há necessidade de análise da influência de múltiplas variáveis ao mesmo tempo e sua extensão sobre um evento específico, o gestor deve lançar mão técnicas multivariadas de análise (as técnicas multivariadas de análise são evoluções de técnicas univariadas) para obter à compreensão dos dados e a consequente prospecção de informação útil à tomada de decisão (HAIR et al., 2009).

Devido às características da problemática deste trabalho e de suas variáveis, a ferramenta estatística selecionada para análise dos dados foi a regressão logística. Segundo Figueira (2006), situações em que a variável dependente expressa é de natureza qualitativa, o método dos mínimos quadrados não oferece resultados satisfatórios. Nestas situações, a regressão logística permite calcular ou prever a ocorrência de um evento específico. De acordo com Nakamura (2013), o modelo de regressão logística caracteriza-se pelo fato de que a variável dependente possui distribuição de Bernoulli, assumindo os valores 0 e 1, podendo ser denotada por Yi, onde: 1, se o i-ésimo elemento amostral possui a característica de interesse e 0 , caso contrário.

Os atributos são, por sua vez, representados pelas variáveis que compõe o modelo. No caso da regressão logística, as variáveis podem indicar tanto uma medida como a renda, peso, ou no caso desta pesquisa, o valor unitário dos itens licitados ou a quantidade de itens do Pregão. Outras variáveis podem, ainda, identificar características como, se a compra foi parcelada ou não, se os itens foram licitados em lotes ou não. De acordo com Nakamura (2013), ambas as situações podem existir em um modelo de regressão logística. No primeiro caso as variáveis são classificáveis como quantitativas e são caracterizadas pela possibilidade de mensuração matemática de seus valores. No segundo caso, as variáveis são qualitativas, não sendo possível nenhum tipo de mensuração matemática.

Quando comparada a duas outras ferramentas estatísticas, a análise discriminante e a regressão múltipla, os modelos logit possuem certas semelhanças com ambas. Devido à natureza dicotômica da variável dependente existe semelhança entre o logit e a análise discriminante, no entanto, ao contrário desta, não se faz necessária a determinação de scores de corte além da possibilidade de inserção de variáveis não métricas dentre as variáveis explicativas (HAIR et al., 2009). Além disso, o emprego do logit é mais adequado quando se trata apenas de dois possíveis grupos (variável dependente binária) e quando os pressupostos de normalidade e de igualdade das variâncias e covariâncias da análise discriminante não são atendidos. No que tange a regressão múltipla, a principal distinção entre esta e os modelos logit reside no fato de que neste último o objetivo é determinar a probabilidade de ocorrência de um evento (HAIR et al., 2009). Gujarati e Porter (2012) apresentam sete características do modelo logit, a saber:

1. Os logits não são limitados podendo variar de $-\infty \mathrm{a}+\infty$, sendo a probabilidade limitada entre 0 e 1 por necessidade;

2. $\quad$ logit é linear em relação a $X$, mas a probabilidade não;

3. É possível introduzir no modelo tantos regressores quanto necessário, desde que em conformidade com a teoria;

4. Quando o logit for positivo, significa que caso os valores dos regressores aumentem, aumentam as chances da ocorrência do evento (quando indicado por 1) ocorrendo o oposto quando logit for negativo; 
5. $\quad \mathrm{O}$ coeficiente angular determinado por $\nabla$ mede a variação do logit para cada unidade de $\mathrm{X}$ e o intercepto determina as chances favoráveis à ocorrência do evento;

6. É possível a determinação da probabilidade da ocorrência do evento uma vez conhecidas as estimativas do coeficiente angular e do intercepto;

7. No modelo logit supõem-se que o log das razões das chances é linearmente relacionado com Xi.

\section{METODOLOGIA}

A pesquisa pode ser classificada como de natureza aplicada, uma vez que busca apontar causas de insucesso de itens de pregões eletrônicos abertos por dez universidades federais com sede no nordeste (Quadro 1). Silva e Menezes (2000, p. 16) corroboram esta classificação inicial ao afirmar que o objetivo de uma pesquisa aplicada é "gerar conhecimentos para aplicação prática dirigida à solução de problemas específicos".

A ferramenta estatística utilizada foi a regressão logística, cujos cálculos foram realizados com o auxilio do Microsoft Excel e do programa de estatística IBM SPSS versão 21 e os dados obtidos foram tratados e analisados. Em consequência disso, a pesquisa pode ser classificada quanto sua abordagem como quantitativa o método utilizado foi o estatístico. Conforme Martins e Theóphilo (2009, p. 107), as "pesquisas quantitativas são aquelas em que os dados e as evidências coletados podem ser quantificados e mensurados”.

No que tange à forma de estudo, a pesquisa pode ser classificada como explicativa, uma vez que visa possibilitar a identificação e entendimento de variáveis que influenciam no resultado dos certames licitatórios. Este é um tipo de pesquisa mais complexo uma vez que "vai além do registro, da análise, da classificação e da interpretação dos fenômenos em estudo procurando quais são os seus fatores determinantes" (PRESTES, 2008, p. 26).

Quadro 1 - Quantidade de pregões abertos em 2013

\begin{tabular}{|l|c|}
\hline \multicolumn{1}{|c|}{ Universidade } & Pregões \\
\hline Fundação Universidade Federal do Piauí & 158 \\
\hline Mec-Universidade Federal/Se & 150 \\
\hline MEC/Uf-Universidade Federal da Paraíba/PB & 76 \\
\hline Universidade Federal da Bahia - UF/BA & 109 \\
\hline Universidade Federal de Alagoas & 77 \\
\hline Universidade Federal de Pernambuco & 289 \\
\hline Universidade Federal do Ceará & 250 \\
\hline Universidade Federal Rural de Pernambuco & 150 \\
\hline Universidade Federal do Rio Grande do Norte & 107 \\
\hline Fundação Universidade do Maranhão & 130 \\
\hline \multicolumn{1}{|c|}{ Total } & $\mathbf{1 4 9 6}$ \\
\hline
\end{tabular}

Nota: fonte: Comprasnet.gov.br, 2014. 
O procedimento de análise foi estabelecido com base no que propõe a obra Análise Multivariada de Dados (2009) de autoria de Joseph F. Hair Junior, William C. Black, Barry J. Babin, Rolph E. Anderson e Ronald L. Tatham. No livro, os autores estabelecem 6 estágios para construção e utilização de um modelo de regressão logística: Objetivos da Pesquisa, Planejamento de pesquisa, Suposições estatísticas, Estimação do Modelo, Interpretação dos Resultados e Validação dos Resultados.

O primeiro estágio estabelecido por Hair et al. (2009), busca verificar a existência no problema de pesquisa, de características que o tornem passível o emprego da regressão logística como ferramenta de análise. Situação verificada, na relação da variável dependente (binária) com as variáveis independentes (métricas e não métricas);

O segundo estágio proposto por Hair et al. (2009), trata da seleção e classificação das variáveis (Quadro 2), bem como o dimensionamento da amostra a ser utilizada. Inicialmente foram selecionadas 11 variáveis, com base na teoria e nos 5 anos de experiência do pesquisador na área de licitações (Quadro 2: variáveis v.1 a v.11). Em função de suas características, parte delas, foi tratada dando origem a novas (Quadro 2: variáveis v.12 a v.15). O tamanho da amostra foi de 550, 55 observações por variável independente utilizada. Atendendo assim ao que Hair et al. (2009) propõem de no mínimo 20 observações por variável independente e ao que Coster (2009) indica mínimo de 500 observações no total da amostra para melhoria da qualidade da análise. 


\section{Quadro 2 Variáveis pré-selecionadas}

\begin{tabular}{|c|c|c|c|c|c|c|}
\hline 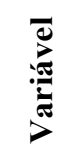 & Nome & Rótulo & Uీ & 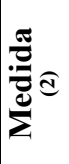 & Valores & $\begin{array}{l}\text { Medida } \\
\text { Corretiva }\end{array}$ \\
\hline V.1 & Situação & $\begin{array}{l}\text { Indica se o item foi aceito ou não pelo } \\
\text { pregoeiro. }\end{array}$ & $\mathrm{D}$ & $\mathrm{N}$ & $\begin{array}{c}1 \text { - aceito } \\
0 \text { - cancelado }\end{array}$ & Nenhuma \\
\hline V.2 & Quantidade & $\begin{array}{l}\text { Indica a quantidade pretendida para } \\
\text { aquisição. }\end{array}$ & I & M & $\begin{array}{l}\text { Em unidades } \\
\text { de } 1 \text { a } 800.000\end{array}$ & $\begin{array}{l}\text { Logaritmo } \\
\text { base } 10\end{array}$ \\
\hline V.3 & Vlr. Unitário & $\begin{array}{l}\text { Indica o valor unitário estimado pela } \\
\text { Administração. }\end{array}$ & I & M & $\begin{array}{c}\text { Em reais } \\
\text { de } 0,01 \text { a } 5.000,00\end{array}$ & $\begin{array}{l}\text { Logaritmo } \\
\text { base } 10\end{array}$ \\
\hline V.4 & $\begin{array}{l}\text { Aquisição p/ } \\
\text { SRP }\end{array}$ & $\begin{array}{l}\text { Indica se o item em questão será contratado } \\
\text { de maneira parcelada por meio de sistema de } \\
\text { registro de preços. }\end{array}$ & I & $\mathrm{N}$ & $\begin{array}{l}1 \text { - Parcelado SRP } \\
0 \text { - Único Pedido }\end{array}$ & Nenhuma \\
\hline V.5 & Compra $\mathrm{p} /$ lote & $\begin{array}{l}\text { Indica se o item foi licitado em conjunto ou } \\
\text { individualmente. }\end{array}$ & I & $\mathrm{N}$ & $\begin{array}{c}1-\text { Lote } \\
0 \text { - item a item }\end{array}$ & Nenhuma \\
\hline V.6 & $\begin{array}{l}\text { Qnt. de itens } \\
\text { licitados }\end{array}$ & Indica o número de itens do processo. & I & M & $\begin{array}{l}\text { Em unidades } \\
\text { de } 1 \text { a } 376\end{array}$ & $\begin{array}{c}\text { Logaritmo } \\
\text { base } 10\end{array}$ \\
\hline V.7 & $\begin{array}{l}\text { Dist. da região } \\
\text { sudeste }\end{array}$ & $\begin{array}{l}\text { Indica a distância média da sede da IFES em } \\
\text { relação às capitais da região sudeste. }\end{array}$ & I & M & $\begin{array}{c}\text { Em km } \\
\text { de } 1.757,25 \text { a } \\
3.029,25 \\
\end{array}$ & Nenhuma \\
\hline V.8 & $\begin{array}{l}\text { Qnt. de } \\
\text { Fornecedores }\end{array}$ & $\begin{array}{l}\text { Indica o número de fornecedores cadastrados } \\
\text { no SICAF no estado onde se localiza a IFES. }\end{array}$ & I & M & $\begin{array}{c}\text { Em unidades } \\
\text { de } 2.500 \text { a } 12.484\end{array}$ & Nenhuma \\
\hline V.9 & Var. IGPM & $\begin{array}{l}\text { Indica a variação do IGPM do mês de } \\
\text { abertura do Pregão em relação ao mês } \\
\text { anterior. }\end{array}$ & I & M & $\begin{array}{c}\text { Em percentual } \\
\text { de }-0,64 \% \text { a } 1,35 \%\end{array}$ & Nenhuma \\
\hline V.10 & Var. US\$ & $\begin{array}{l}\text { Indica a variação da cotação US\$ frente ao } \\
\text { Real do mês de abertura do Pregão em } \\
\text { relação ao mês anterior. }\end{array}$ & $\mathrm{I}$ & M & $\begin{array}{c}\text { Em percentual } \\
\text { de }-0,08 \% \text { a } 0,14 \%\end{array}$ & Nenhuma \\
\hline V.11 & $\begin{array}{l}\text { Quantidade de } \\
\text { palavras }\end{array}$ & $\begin{array}{l}\text { Indica a quantidade de palavras utilizadas na } \\
\text { descrição complementar do item. }\end{array}$ & I & $\mathrm{M}$ & $\begin{array}{l}\text { Em unidades } \\
\text { de } 0 \text { a } 225\end{array}$ & $\begin{array}{l}\text { Logaritmo } \\
\text { base } 10\end{array}$ \\
\hline V.12 & Demanda & $\begin{array}{l}\text { Agrupa os valores referentes a quantidades } \\
\text { com base nos decis calculados a partir da } \\
\text { população. }\end{array}$ & I & $\begin{array}{l}\mathrm{V} . \\
12\end{array}$ & $\begin{array}{l}\text { Decis da variável } \\
\text { V.2 }\end{array}$ & Nenhuma \\
\hline V.13 & Faixa de valor & $\begin{array}{l}\text { Agrupa os valores referentes ao valor unitário } \\
\text { estimado com base nos decis calculados a } \\
\text { partir da população. }\end{array}$ & I & $\begin{array}{l}\text { V. } \\
13\end{array}$ & $\begin{array}{l}\text { Decis da variável } \\
\text { V.3 }\end{array}$ & Nenhuma \\
\hline V.14 & Detalhamento & $\begin{array}{l}\text { Agrupa os valores referentes à quantidade de } \\
\text { palavras com base nos quartis calculados a } \\
\text { partir da população. }\end{array}$ & I & $\begin{array}{l}\text { V. } \\
14\end{array}$ & $\begin{array}{l}\text { Quartis da variável } \\
\text { V.11 }\end{array}$ & Nenhuma \\
\hline V.15 & $\begin{array}{l}\text { Itens/ } \\
\text { Fornecedor }\end{array}$ & $\begin{array}{l}\text { Razão entre o número de itens em relação ao } \\
\text { número de fornecedores }\end{array}$ & I & M & Números inteiros & Nenhuma \\
\hline
\end{tabular}

(1) D para variável dependente e I para variável independente

(2) $\mathrm{M}$ para variáveis métricas e $\mathrm{N}$ para variáveis não métricas

Nota: Fonte: Elaborado pelo autor. 
O terceiro estágio proposto por Hair et al. (2009), pode ser entendido como a verificação da adequação das variáveis à técnica estatística selecionada. No caso, aos pressupostos de linearidade, normalidade, homocedasticidade e multicolinearidade das variáveis, além da presença e tratamento de outliers. Para tanto, deu-se início a análise da estatística descritiva e da assimetria da amostra (Quadro 3).

\section{Quadro 3 -Calculo da assimetria e curtose da amostra}

\begin{tabular}{|c|c|c|c|c|c|c|c|}
\hline Variável & 莺 & 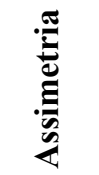 & 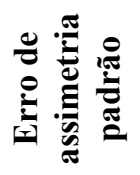 & 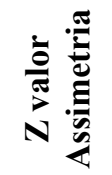 & 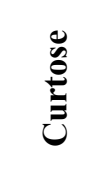 & 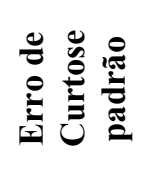 & 章总 \\
\hline V.2 Quantidade & 3224,15 & 17,18 & 0,11 & 156,16 & 337,98 & 0,21 & 1609,43 \\
\hline V.3 Valor Unitário & 96,59 & 6,32 & 0,11 & 57,41 & 53,80 & 0,21 & 256,19 \\
\hline V.6 Qnt. de itens Licitados & 133,03 & 0,72 & 0,11 & 6,55 & $-0,50$ & 0,21 & $-2,38$ \\
\hline V.7 Dist. Sudeste & 2485,77 & $-0,27$ & 0,11 & $-2,45$ & $-1,27$ & 0,21 & $-6,05$ \\
\hline V.8 Qnt. fornecedores & 7053,23 & 0,21 & 0,11 & 1,91 & $-1,66$ & 0,21 & $-7,90$ \\
\hline V.9 Var. IGPM & $-0,05$ & 1,25 & 0,11 & 11,36 & 0,58 & 0,21 & 2,76 \\
\hline V.10 Var. US\$ & 0,02 & 0,00 & 0,11 & 0,00 & $-1,31$ & 0,21 & $-6,24$ \\
\hline V.11 Qnt. Palavras na descrição & 20,78 & 3,08 & 0,11 & 28,00 & 13,38 & 0,21 & 63,71 \\
\hline V.15 Itens/fornecedores & 0,0239 & 0,892 & 0,11 & 8,18 & $-0,276$ & 0,21 & $-1,27$ \\
\hline
\end{tabular}

Nota: Fonte: Dados da Pesquisa

O primeiro passo adotado no sentido de confirmar a regressão logística como ferramenta a ser utilizada, deteve-se na verificação da ocorrência de outliers. A priori, o comportamento nestas situações poderia ser induzido à eliminação daquele valor anormal, no entanto, Hair et al. (2009) afirma que os outliers devem ser retirados apenas se comprovado que aquele valor não é representativo de nenhuma parcela da população. Nas V.1, V4 e V.5 não foram localizados outliers.

Já no caso das variáveis V.2 e V.3 optou-se por criar variáveis em escala com base em medidas de tendência (quartis e decis) uma vez que não foram identificados erros de lançamento e a amplitude destas variáveis é significativa, gerando-se as variáveis V.12, V.13. Nas demais variáveis não foram localizados outliers que indicassem a necessidade de ação corretiva, exceto na variável v.8, onde foram identificadas 19 observações anômalas que foram excluídas.

Uma das "suposições mais importantes em análise multivariada é a normalidade" (HAIR et al 2009, p. 82), situação que será verificada nos próximos parágrafos. Ainda segundo os autores, é de fundamental importância que seja avaliada sua ocorrência em todas as variáveis métricas (Quadro 4). 


\section{Quadro 4 Calculo da assimetria e curtose da amostra}

\begin{tabular}{|c|c|c|c|c|c|c|c|}
\hline Variável & 丞 & 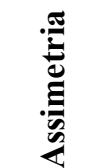 & 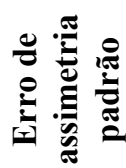 & 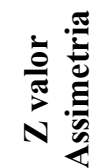 & 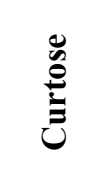 & 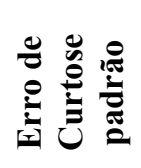 & 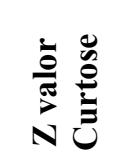 \\
\hline V.2 Quantidade & 3224,15 & $\overline{17,18}$ & 0,11 & 156,16 & 337,98 & 0,21 & 1609,43 \\
\hline V.3 Valor Unitário & 96,59 & 6,32 & 0,11 & 57,41 & 53,80 & 0,21 & 256,19 \\
\hline V.6 Qnt. de itens Licitados & 133,03 & 0,72 & 0,11 & 6,55 & $-0,50$ & 0,21 & $-2,38$ \\
\hline V.7 Dist. Sudeste & 2485,77 & $-0,27$ & 0,11 & $-2,45$ & $-1,27$ & 0,21 & $-6,05$ \\
\hline V.8 Qnt. fornecedores & 7053,23 & 0,21 & 0,11 & 1,91 & $-1,66$ & 0,21 & $-7,90$ \\
\hline V.9 Var. IGPM & $-0,05$ & 1,25 & 0,11 & 11,36 & 0,58 & 0,21 & 2,76 \\
\hline V.10 Var. US\$ & 0,02 & 0,00 & 0,11 & 0,00 & $-1,31$ & 0,21 & $-6,24$ \\
\hline V.11 Qnt. Palavras na descrição & 20,78 & 3,08 & 0,11 & 28,00 & 13,38 & 0,21 & 63,71 \\
\hline V.15 Itens/fornecedores & 0,0239 & $\mathbf{0 , 8 9 2}$ & 0,11 & 8,18 & $-0,276$ & 0,21 & $-1,27$ \\
\hline
\end{tabular}

Nota: Fonte: Dados da Pesquisa

De acordo com Pilati e Porto (2014), um indício de não normalidade na distribuição é o valor do desvio padrão maior que a média da variável. Esta situação pode ser observada nas variáveis: quantidade V.2 (valor unitário V.3), V.10 (variação do dólar) e V.9 (variação do IGPM) (Quadro 4). A constatação da não distribuição normal das variáveis V.2 (quantidade), V.3 (valor unitário), V.8 (Qnt. fornecedores) e V.11 (quantidade de palavras) foi comprovada com a aplicação do teste de Kolmogorov-Smirnov. Nele, em sendo o resultado significativo (com p> 0,05) não há distribuição normal, situação constatada neste conjunto de variáveis. Segundo Hair et al. (2009) quando a indicação de não normalidades, assimetria positiva e um pico na parábola a ação corretiva o calculo do logaritmo da variável (Quadro, 4),

Ainda de acordo com Hair et al. (2009), em casos de leve variação assimétrica (A assimetria, no caso desta pesquisa, foi calculada com o auxilio do software SPSS versão 21) não é necessário adoção de medida corretiva da normalidade. Diante disso, optou-se pela manutenção das variáveis V.7 (assimetria: -0,27), V.8(assimetria: + 0,21), V.9 (assimetria: +1,25), V.10 (assimetria: + 0,02), e V.15 (assimetria: + 0,892), sem a adoção de medidas de correção (Quadro, 2).

Outro ponto a ser observado no que tange a adequação das variáveis à regressão logística é sua homocestasticidade (GUJARATI; PORTER 2011). Para este trabalho optou-se pelo emprego do teste de Levene calculado por meio do SPSS V.21, segundo Almeida, Silva e Nobre (2008), este teste permite verificar a homogeneidade da variância.

O ultimo ponto de checagem da aplicabilidade da regressão logística é a verificação da existência de multicolinearidade entre as variáveis. O estudo da correlação tem por objetivo identificar o quanto o comportamento de uma variável está ligado ao de outra. A correlação pode ser perfeita ou nula. No primeiro caso, o estudo de uma variável pode oferecer toda informação sobre a outra e no segundo caso o contrário (BESSA, 2010).
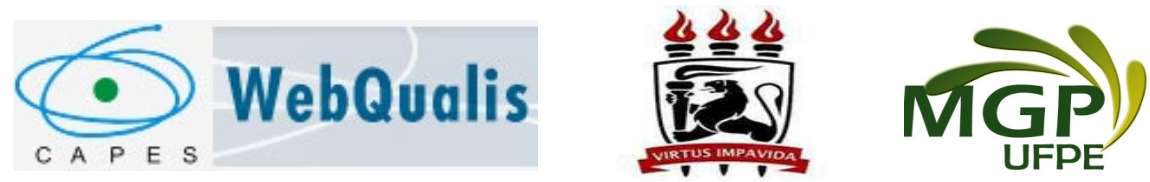

Volume V, Número 1, Abr 2016 
Logicamente, a correlação forte entre a variável dependente e as variáveis explicativas é desejável e benéfico à análise. No entanto, a ocorrência de um alto grau de correlação entre variáveis explicativas torna-se um obstáculo, uma vez que poderia estas variáveis estar explicando a mesma parcela do comportamento da variável dependente. Segundo Levine (2010), há ocorrência da multicolinearidade quando a existe forte correlação entre as variáveis explicativas o que torna difícil determinar qual é o efeito da variável sobre a dependente.

Para verificação da existência de multicolinearidade na amostra optou-se pela análise do fator de inflação da variância ou VIF e a Matriz de correlação (Apêndice 1). No caso do VIF considera-se a existência de multicolinearidade quando este é igual ou superior a dez. No caso da matriz de correlação considerou-se como indicativo de forte multicolinearidade valores superiores a 50\%. A análise do fator de inflação da variância apontou multicolinearidade apenas entre variáveis que são consequência de operações matemáticas de outras. No caso, V.13 (Faixa de valor) com VIF de 9,722, resultado do agrupamento de faixas da variável V.3 (Valor Unitário) e V.12 (Demanda) com VIF de 22,843, consequência do agrupamento da V.2 (Quantidade). Em função disso foram mantidas apenas as variáveis V.3 e V.2. A análise da matriz de correlação (Apêndice 1) permite identificar a presença de forte correlação negativa entre as variáveis quantidade e valor unitário. Segundo Gujarati e Porter (2011) é possível manter variáveis que apresentem multicolinearidade sem a adoção de nenhum tipo de medida corretiva. No caso dessas duas variáveis optou-se pela manutenção de ambas.

\section{ESTIMAÇÃO DO MODELO}

O quarto estágio proposto por Hair et al. (2009) trata da estimação do modelo, sua a avaliação e ajuste geral. Inicialmente, foram excluídas dos cálculos as variáveis V.12, V.13 e V.14 (Quadro 2) por dois motivos. Primeiro no caso de V.12 e V.13 a multicolinearidade destas com as variáveis V.2 e V.3, respectivamente. O segundo motivo refere-se ao fato de que uma vez tendo sido realizada a devida correção quanto à normalidade da distribuição optou-se pela exclusão dos agrupamentos, situação em que também se enquadra V.14. Outro fator a ser destacado antes da apresentação dos cálculos é que esta foi realizada sem a inserção da constante. Nos testes iniciais a constante não se apresentou significativa a 5\%. Além disso, sua presença no modelo influenciava negativamente a capacidade preditiva com R quadrado Nagelkerke R inferior a 15\% e R de quadrado Cox \& Snell menor que $10 \%$.

Considerando todas as varáveis selecionadas foi estimado o modelo com o auxílio do SPSS versão 21 em uma amostra com 524 observações e uma distribuição casos com 21,4\% de itens cancelados e 78,4\% de itens aceitos. Nestas condições, o modelo gerado obteve R quadrado Nagelkerke R de 35,75\% e R de quadrado Cox \& Snell 47,6\% significativos com p > 0,000. No entanto, o sistema indicou a presença de redundâncias nos cálculos o que não permitiu a estimação do Qui-quadrado. Por fim foram selecionadas apenas as variáveis com níveis de significância altos ( $\mathrm{p}>0,05)$ : V.2 Quantidade demanda; V.3 Valor unitário do item; V.4 Aquisição por SRP; V.7 Distancia do Sudeste; V.15 Itens/ Fornecedores. A partir deste conjunto de variáveis foi estimado o modelo analisado. O Quadro 5, apresenta um resumo geral dos dados utilizados, 96,40\% das 524 observações foram efetivamente incluídas na análise dos dados. 


\section{Quadro 5 -Resumo do processamento de casos}

\begin{tabular}{|c|c|c|c|}
\hline \multicolumn{2}{|c|}{ Casos não ponderados } & N & Porcentagem \\
\hline \multirow{3}{*}{ Casos selecionados } & Incluído na análise $^{\text {a }}$ & 505 & 96,40 \\
\cline { 2 - 4 } & Casos ausentes & 19 & 3,60 \\
\cline { 2 - 4 } & Total & 524 & 100,00 \\
\hline \multicolumn{2}{|c|}{ Casos não selecionados } & 0 & 0,00 \\
\hline \multicolumn{2}{|c|}{ Total } & 524 & 100,00 \\
\hline
\end{tabular}

${ }^{\text {a. }}$ Se a ponderação estiver em vigor, veja a tabela de classificação para o número total de casos.

Nota: Fonte: Dados da Pesquisa

O quadro 6 por sua vez apresenta a significância da influência de cada uma das cinco variáveis selecionadas sobre o evento estudado e a possibilidade de influência na capacidade preditiva do modelo com a inserção de novas variáveis por meio da análise da estatística global.

\section{Quadro 6 - Variáveis não presentes na equação}

\begin{tabular}{|c|c|c|c|c|c|}
\hline \multicolumn{3}{|c|}{} & Pontuação & df & Sig. \\
\hline \multirow{4}{*}{ Etapa 0 } & \multirow{4}{*}{ Variáveis } & V.2 Quantidade demanda & 153,567 & 1 & 0,000 \\
\cline { 3 - 6 } & & V.3 Valor unitário do item & 128,028 & 1 & 0,000 \\
\cline { 3 - 6 } & & V.4 Aquisição por SRP & 117,395 & 1 & 0,000 \\
\cline { 3 - 6 } & & V.7 Dist. do Sudeste & 167,546 & 1 & 0,000 \\
\cline { 3 - 6 } & & V.15 Itens/ Fornecedores & 145,348 & 1 & 0,000 \\
\cline { 3 - 6 } & & Estatísticas globais & $\mathbf{1 8 7 , 7 4 7}$ & $\mathbf{5}$ & $\mathbf{0 , 0 0 0}$ \\
\hline
\end{tabular}

Os quadros 7 e 8 apresentam, respectivamente, a significância do modelo em si e o resultado dos pseudos $\mathrm{R}^{2}$ de quadrado Cox \& Snell Nagelkerke. Por fim o quadro 9 e 10 apresentam o nível global de acerto do modelo as a influência de cada uma da variáveis independentes sobre este.

\section{Quadro 7 - Testes de coeficientes de modelo Omnibus}

\begin{tabular}{|c|c|c|c|c|}
\hline \multicolumn{2}{|c|}{} & Qui-quadrado & df & Sig. \\
\hline \multirow{3}{*}{ Etapa 1 } & Etapa & 209,548 & 5 & 0,000 \\
\cline { 2 - 5 } & Bloco & 209,548 & 5 & 0,000 \\
\cline { 2 - 5 } & Modelo & 209,548 & 5 & 0,000 \\
\hline
\end{tabular}

Nota: Fonte: Dados da Pesquisa 


\section{Quadro 8 - Resumo do modelo}

\begin{tabular}{|c|c|c|c|}
\hline Etapa & $\begin{array}{c}\text { Verossimilhança } \\
\text { de } \log -2\end{array}$ & $\begin{array}{c}\text { R quadrado Cox } \\
\& \text { Snell }\end{array}$ & $\begin{array}{c}\text { R quadrado } \\
\text { Nagelkerke }\end{array}$ \\
\hline 1 & $490,530^{\mathrm{a}}$ & 0,340 & 0,453 \\
\hline
\end{tabular}

a. Estimação encerrada no número de iteração 5 porque as estimativas de parâmetro mudaram em menos de 0,001 .

Nota: Fonte: Dados da Pesquisa

\section{Quadro 9 - Tabela de classificação ${ }^{a}$}

\begin{tabular}{|c|c|c|c|c|c|}
\hline & \multicolumn{3}{|c|}{ Previsto } \\
\hline & & & \multicolumn{2}{|c|}{ Situação } & \multirow{2}{*}{$\begin{array}{c}\text { Porcentagem } \\
\text { correta }\end{array}$} \\
\hline & & & 0 & 1 & \\
\hline \multirow{3}{*}{ Etapa 1} & \multirow{2}{*}{ V.1 Situação } & 0 & 5 & 104 & 4,6 \\
\hline & & 1 & 0 & 396 & 100,0 \\
\hline & \multicolumn{2}{|c|}{ Porcentagem global } & & & $79,4 \%$ \\
\hline
\end{tabular}

a. $\mathrm{O}$ valor de corte é 0,500

Nota: Fonte: Dados da Pesquisa

\section{Quadro 10 - Variáveis na equação}

\begin{tabular}{|c|c|c|c|c|c|c|c|}
\hline & & B & S.E. & Wald & df & Sig. & $\operatorname{Exp}(B)$ \\
\hline \multirow{5}{*}{ 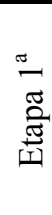 } & V.2 Quantidade & 0,638 & 0,134 & 22,679 & 1 & 0,000 & 1,893 \\
\hline & V.3 Valor unitário & 0,636 & 0,153 & 17,268 & 1 & 0,000 & 1,890 \\
\hline & V.4 Aquisição por SRP & $-0,742$ & 0,281 & 6,956 & 1 & 0,008 & 0,476 \\
\hline & V.7 Distância da Sudeste & 0,000 & 0,000 & 4,177 & 1 & 0,041 & 1,000 \\
\hline & V.15 Itens/Fornecedores & 0,491 & 0,181 & 7,364 & 1 & 0,007 & 1,634 \\
\hline
\end{tabular}

Variáveis inseridas na etapa 1: Quantidade, Valor unitário, Aquisição por SRP, Distância do Sudeste, Itens/Fornecedores.

Nota: Fonte: Dados da Pesquisa 


\section{INTERPRETAÇÃO E VALIDAÇÃO DOS RESULTADOS}

Neste tópico, foi dada continuidade à sequência proposta por Hair et al. (2009) para a construção de um modelo de análise multivariada fundamentado na regressão logística. Trata-se do quinto e do sexto estágios propostos pelos autores, o da interpretação e o da validação dos resultados. O objetivo é analisar as variáveis que compõem o modelo propriamente dito e sua influência sobre o resultado do Pregão. Considerando a população total de 31 mil observações $21,6 \%$ dos itens licitados foram cancelados, na etapa final do processo de licitação e as Universidades Federais de Pernambuco e do Rio Grande do Norte apresentaram as maiores taxas de insucesso, 19,47\% dos itens licitados por estas universidades foram cancelados. Enquanto a Universidade Federal de Alagoas e a Fundação Universidade do Maranhão cancelaram apenas 2,65\% e 4,42\% dos itens que licitaram, respectivamente.

\subsection{Validação dos resultados}

O sexto e último estágio proposto por Hair et al. (2009) foi o da validação dos resultados. Segundo os autores a validação pode ser realizada por meio de uma amostra de testes. Neste caso, foi extraída outra amostra aleatória de 524 observações. Calculada a regressão considerando as variáveis utilizadas no modelo original obteve-se os seguintes resultados:

a) O modelo de extraído da amostra de teste foi significativo com $\mathrm{p}>0,000$;

b) Os valores dos R2 de Cox \& Snell e Nagelkerke foram semelhantes aos obtidos na amostra inicial 36\% e $48 \%$ respectivamente;

c) Após a realização do teste de Hosmer e Lemeshow, é possível inferir que o modelo ajusta-se de forma adequada, uma vez que a hipótese de inadequação pode ser excluída considerando o qui-quadrado de 4,285 com p>0,831(Quadro 11).

\section{Quadro 11- Tabela de contingência para teste de Hosmer e Lemeshow}

\begin{tabular}{|c|c|c|c|c|c|c|}
\hline \multicolumn{2}{|c|}{} & \multicolumn{2}{c|}{ Situação $=0$} & \multicolumn{2}{c|}{ Situação=1 } & \multirow{2}{*}{ Total } \\
\cline { 3 - 7 } \multicolumn{2}{|c|}{} & Observado & Esperado & Observado & Esperado & \\
\hline \multirow{5}{*}{ Etapa 1 } & 1 & 24 & 24,593 & 29 & 28,407 & 53 \\
\cline { 2 - 7 } & 2 & 15 & 19,025 & 38 & 33,975 & 53 \\
\cline { 2 - 7 } & 3 & 15 & 16,224 & 38 & 36,776 & 53 \\
\cline { 2 - 7 } & 4 & 18 & 13,837 & 35 & 39,163 & 53 \\
\cline { 2 - 7 } & 5 & 9 & 11,365 & 44 & 41,635 & 53 \\
\cline { 2 - 7 } & 6 & 9 & 9,403 & 44 & 43,597 & 53 \\
\cline { 2 - 7 } & 8 & 9 & 7,392 & 44 & 45,608 & 53 \\
\cline { 2 - 7 } & 9 & 4 & 5,714 & 47 & 47,286 & 53 \\
\cline { 2 - 7 } & 10 & 2 & 1,773 & 46 & 46,075 & 53 \\
\hline
\end{tabular}

Nota: Fonte: Dados da Pesquisa 


\section{CONSIDERAÇÕES FINAIS}

Este trabalho teve por principal objetivo identificar as variáveis que afetam à existência e aceitação de propostas em pregões eletrônicos. Embora o pregão tenha sido implantado com o objetivo de tornar o procedimento de compra estatal mais ágil, a rigidez burocrática do procedimento foi mantida. Assim cancelamentos de itens nos processos podem dificultar o atendimento da demanda.

Esta pesquisa identificou 31 mil itens classificáveis como itens de consumo. Deste total 21,6\% foram cancelados. O objetivo foi identificar fatores que influenciam esta situação. Das quinze variáveis selecionadas (Quadro 2) apenas cinco, apresentaram correlação significativa em relação ao evento estudado e destas somente quatro possuíam influência não nula, a saber: quantidade demandada, valor unitário do item, opção por formação de ata de registro de preços e a relação entre o número de fornecedores e quantidade de itens no edital.

Observou-se que quantidades maiores podem reduzir as chances de cancelamento de itens. Os cálculos a partir da amostra indicaram que o aumento da quantidade demandada, aumenta em quase duas vezes a probabilidade de sucesso. Assim, para minimizar as chances de cancelamento de um item a Administração pode, por exemplo, participar de compras compartilhadas com outros órgãos, objetivando a abertura de procedimentos com quantidades maiores.

O valor do item, também, apresentou forte influência sobre o resultado final. A razão de chances de 1,890 da variável valor unitário indica que itens com valores maiores tem menor possibilidade de cancelamento. Considerando que a Administração não determina o preço de mercado, nem pode adquirir itens com valor superior ao estimado na fase interna, pode-se inferir que para maximixar as chances de sucesso, o ajuste da demanda licitada por processo pode, também, representar nestes casos, um mecanismo possível de redução das chances de cancelamento. E neste sentido, as compras compartilhadas podem também representar um meio factível para este fim.

A terceira variável com reflexos positivos sobre o resultado final do item, foi a razão entre o número de itens e a quantidade de fornecedores cadastrados no estado, onde a IFES tem sede. Ampliando a quantidade de itens em um Pregão, poderia a Administração reduzir a possibilidade de insucesso do item. Isto é, considerando que um fornecedor pode, ao término da fase de lances, ser detentor do menor lance de apenas um item, o volume de venda previsto pode tornar o contrato pouco atrativo, assim, processos com mais itens, logicamente de mesma natureza, isto é, de um mesmo mercado, poderiam reduzir as chances de cancelamento.

A opção por formação de Ata de Registro de Preços - ARP, por sua vez, reduz a eficiência do procedimento de compra, no que tange a aceitação do item no Pregão eletrônico. Esta situação poderia ser explicada por características deste procedimento. Em primeiro lugar, o fornecedor deve manter o preço por um ano, prazo de vigência da ata, o que pode gerar em produtos mais suscetíveis a oscilação de preços, uma possibilidade maior de fracasso. Outro ponto que possivelmente pode influenciar negativamente no caso das ARP, é o fato de que não há a priori nenhuma obrigatoriedade de compra por parte da Administração e muito menos uma indicação do volume de cada pedido. 
Nesse sentido, um fornecedor que vence uma licitação para mil unidades de um determinado item, pode ter de atender mil pedidos de uma unidade ou um único pedido a qualquer momento durante a vigência da ata. Esta situação poderia então afetar a eficiência do procedimento. No entanto, as variáveis obtidas não permitem precisa-la.

Diante do que foi dito, pode-se concluir, que o sucesso do item está vinculado ao volume licitado, tanto no que diz respeito à quantidade licitada, ao número de itens constantes no edital, ao valor do item e a estratégia de fornecimento exigida.

Este trabalho teve como limitações identificar variáveis que permitissem os efeitos do mercado sobre o resultado e que mensurasse qualitativamente o instrumento convocatório e o reflexo dele sobre a licitação. Nesse sentido são sugestões para trabalhos futuros: Análise qualitativa do instrumento convocatório; Análise da correlação negativa da Ata de registro de preços sobre o resultado do Pregão; Até que ponto a metodologia de determinação do preço estimado é precisa.

\section{REFERÊNCIA}

ALMEIDA, Antônia de; SILVIA, Elian; NOBRE, Juvêncio. Modificações e alternativas aos testes de Levene e de Brown e Forsythe para igualdade de variâncias e médias. Revista Colombiana de Estadística. Diciembre 2008, volumen 31, no. 2, pp. 241 a 260. Disponível em: http://www.emis.de/journals/RCE/V31/v31n2a08AlmeidaElianNobre.pdf. Acessado em: 03/01/2015.

ALMEIDA, Tatiana Behrsing Burlamaqui de. Avaliação do sistema de Pregão eletrônico e sua adequação a uma instituição de pesquisa e ensino em ciência e tecnologia em saúde - CpqAM. Dissertação. (2006). Mestrado profissional em Saúde Pública do Centro de Pesquisas Aggeu Magalhães.

ALVES, Luiz Claudio Otranto; SILVA, Anderson Soares; FONSECA; Ana Carolina Pimentel Duarte da. Implicações da Adoção do Modelo de Merchant na Avaliação do Uso da TI para Controle Gerencial do Serviço Público - Análise do Portal Comprasnet. Revista Contabilidade Vista \& Revisada, v. 19, n. 1, p. 83-108, jan./ mar. 2008.

ANTUNES; Pedro Daniel Limão Meda. Gestão de compras. Caso de estudo na Newvision. Dissertação para obtenção do Grau de Mestre em Engenharia e Gestão Industrial. Faculdade de Ciências e Tecnologia. Universidade Nova de Lisboa. Lisboa 2012. Disponível em: <http://run.unl.pt/bitstream/10362/8514/1/Antunes_2012.pdf>. Acesso em: 13/05/2014.

BRASIL, Constituição (1988). Constituição da República Federativa do Brasil. Brasília, DF: Senado 1988. Artigo 37, XXI. Disponível em:< www.planalto.gov.br/ccivil_03/constituicao/. Acesso em: 20/12/2013.

. Lei no 8.666, de 21 de junho de 1993. Regulamenta o art. 37, inciso XXI, da licitações e contratos da Administração

Pública e dá outras providências. Disponível em: <www.planalto.gov.br/ccivil_03/leis/18666cons.htm>. Acesso em: 20/03/2013.

, Decreto 3.555 de 8 de agosto de 2000. Aprova o Regulamento para a modalidade de licitação denominada Pregão, para aquisição de bens e serviços comuns. Anexo I, Artigo $2^{\circ}$ caput. Disponível em: $<$ www.planalto.gov.br/ccivil_03/ decreto/D3555.htm>. Acesso em: 20 de janeiro de 2014.

Lei 10.520, de 17 de julho de 2002. Institui, no âmbito da União, Estados, Distrito Federal e Municípios, nos termos do art. 37, inciso XXI, da Constituição Federal, modalidade de licitação denominada Pregão, para aquisição de bens e serviços comuns, e dá outras providências. Disponível em: <http://www.planalto.gov.br/ccivil_03/leis/2002/110520.htm>. Acesso em: 02/02/2013

.Decreto 5.450 de 31 de maio de 2005. Regulamenta o Pregão, na forma eletrônica, para aquisição de bens e serviços comuns, e dá outras providências. Disponível em www.planalto.gov.br/ccivil_03/_ato2004.../2005/decreto/d5450.htm: Acesso em: 20 de janeiro de 2014.

. Tribunal de Contas da União. Licitações e contratos : orientações e jurisprudência do TCU /Tribunal de Contas da União. Brasília: TCU, Secretaria Geral da Presidência: Senado Federal, Secretaria Especial de Editoração e Publicações, 2010. 
. COMPRASNET. Atas de pregões eletrônicos com editais publicados pela Universidade Federal de Pernambuco entre 01 de janeiro de 2012 e 31 de dezembro de 2012. Disponível em: www.comprasnet.gov.br Acessado em: 01/03/2014.

Ministério do Planejamento, Orçamento e Gestão. Informações Gerenciais de Contratações e Compras Públicas: janeiro a dezembro de 2013.(a) Disponível em: http://comprasgovernamentais.com.br/wp-content/uploads/2014/01/01_A_06_INFORMATIVO_COMPRASNET_Dados_Gerais_2013.pdf. Acesso em 31/01/2014.

. Portal do Governo Eletrônico do Brasil. Disponível em www.governoeletronico.gov.br. Acesso em: 20/05/ 2014.

Decreto No 7.892, DE 23 de janeiro de 2013. Regulamenta o Sistema de Registro de Preços previsto no art. 15 da Lei $\mathrm{n}^{\circ}$ 8.666, de 21 de junho de 1993. Disponível em: http://www.planaltqo.gov.br/ccivil_03/_ato2011-2014/2013/Decreto/D7892. htm. Acessado em: 01/11/14

COSTER, Rodrigo. Um alerta sobre o uso de pequenas amostras. Monografia apresentada para obtenção do título de Bacharel em estatística. Universidade Federal do Rio Grande do Sul. Porto Alegre, 2009.

DI PRIETRO, Maria Sylvia Zanella. Direito Administrativo. São Paulo: Atlas, 2013.

FARIA, Evandro Rodrigues de; FERREIRA, Marco Aurélio Marques; SANTOS, Lucas Maia dos; SILVEIRA. Suely F. Ramos. Pregão Eletrônico Versus Pregão Presencial: Estudo Comparativo de Redução de Preços e Tempo. Revista de Contabilidade do Mestrado em Ciências Contábeis da UERJ (online), Rio de Janeiro, v. 16, n. 1, p. 47 - p. 62, jan./abril, 2011. Disponível em: <_Silveira_2011_Pregao-Eletronico-versus-Prega_57.pdf >.

Acesso em: 15/03/2014

FARIA, Evandro Rodrigues de; FERREIRA, Marco Aurélio Marques; SANTOS, Lucas Maia dos; SILVEIRA, Suely de Fátima ramos.Fatores determinantes na variação dos preços dos produtos contratados por Pregão eletrônico. RAP — Rio de Janeiro 44(6):1405-28, nov./dev. 2010. Disponível em: www.scielo.br/scielo.php?pid=S0034-76122010000600007\&script.. Acessado: 03/04/2013.

FARIA, Evandro Rodrigues de; FERREIRA, Marco Aurélio Marques; GONÇALVES, Márcio Augusto. Avaliação dos riscos do Pregão eletrônico: uma abordagem pela teoria da nova economia institucional. Revista de Ciências da Administração • v. 15, n. 37, p. 211-227, dez. 2013.

FARIA, Evandro Rodrigues de; FERREIRA, Marco Aurélio Marques; SANTOS, Lucas Maia dos; SILVEIRA, Suely de Fátima Ramos. Pregão Eletrônico versus Pregão Presencial: Estudo Comparativo e Redução de Preços e Tempo. Revista de Contabilidade do Mestrado em Ciências Contábeis da UERJ (online), Rio de Janeiro, v. 16, n.1, p. 47 - p. 62, jan./abril, 2011.

FERNANDES, Ciro Campos Christo. Política de compras e contratações: trajetória e mudanças na Administração pública federal brasileira. 2010. Tese (Doutorado em Administração) - Escola Brasileira de Administração Pública e de Empresas, Fundação Getulio Vargas, Rio de Janeiro.

FIGUEIRA, Cleonis Viater. Modelos de regressão logística. Dissertação para obtenção do título de mestre em matemática. Universidade Federal do Rio Grande do Sul.Porto Alegre, 2006.

GUJARATI, Damodar N.; PORTES, Dawn C.. Econometria Básica. São Paulo: Bookman, 2011.

HAIR Jr.; Joseph F.; BLACK, William C.; BABIN, Barry J.; ANDERSON, Rolph E.; TATHAM, Ronald L. Análise Multivariada de Dados. Porto Alegre: Bookman, 2009.

JUSTEN FILHO, Marçal. Comentários a Lei de Licitações e Contratos Administrativos. São Paulo: Dialética, 2002. Pregão: comentário à legislação do Pregão comum e eletrônico. São Paulo: Dialética, 2002

LEVINE, David M.; BERENSON, Mark L.; STEPHAN, David. Estatística: Teoria e Aplicações: Usando o Microsoft em Português. Rio de Janeiro: Ltc, 2000. 


\section{REVISTA DE MESTRADOS PROFISSIONAIS}

MARTINS, Gilberto Andrade; THEÓPHILO, Carlos Renato. Metodologia da investigação científica para ciências sociais aplicadas. São Paulo: Atlas, 2009.

MELLO, Celso Antônio Bandeira de. Curso de Direito Administrativo. São Paulo: Malheiros, 2012.

MELLO, Gilmar Ribeiro de; SLOMSK Valmor. Verificando o Endividamento dos Estados Brasileiros:Uma Proposta Utilizando Análise Multivariada de Dados. 30 encontro da ANPAD. 23 A 27 de setembro salvador Bahia. Disponível em: www. anpad.org.br/diversos/trabalhos/EnANPAD/.../2006_APSB632.pdf. Acesso em : 02/04/15

NAKAMURA, Karina Gemhardt. Multicolinearidade em modelos de regressão logística. Dissertação apresentada para obtenção do título de mestre em ciências. Universidade de São Paulo. São Paulo, 2013.

NIEBUHR, Joel de Menezes. Licitação Pública e Contrato Administrativo. Belo Horizonte: Fórum, 2013.

PILATI, Ronaldo; PORTO Juliana B. Apostila para tratamento de dados via SPSS. Universidade de Brasília. Disponível em: www.social.stoa.usp.br. Acessado em: 01/09/14.

PEREIRA, Luiz Carlos Bresser. Da Administração pública burocrática à gerencial. Brasília 1996. Disponível em: http://blogs. al.ce.gov.br/unipace/files/2011/11/Bresser1.pdf; Acesso em: 04/03/2014.

A Reforma do estado dos anos 90: lógica e mecanismos de controle. Brasília: Ministério da Administração Federal e Reforma do Estado, 1997.

Gestão do setor público: estratégia e estrutura para o novo Estado. In: PEREIRA, Luiz Carlos Bresser; SPINK, Peter Kevin (orgs.). Reforma do Estado e Administração Pública Gerencial. Rio de Janeiro: FGV, 2006.

PINDYCK, Robert S.; RUBINDFELD, Daniel L. Econometria: modelos e previsões. Campus. Rio de Janeiro, 2004.

PRESTES, Maria Lucia de Mesquita. A pesquisa e a construção do conhecimento Científico: do planejamento aos textos, da escola a academia. São Paulo: Rêspel, 2008.

SILVA, Edna Lúcia da; MENEZES, Estera Muszkat. Metodologia da Pesquisa e Elaboração de Dissertação. Florianópolis: Laboratório de Ensino a Distância da UFSC, 2000.

TEIXEIRA, Jean Carlos; PENEDO, Antonio Sérgio Torres; ALMEIDA, Reinaldo de. A evolução do processo licitatório com ênfase nos conceitos de economia versus qualidade. Revista Nucleus, v.9, n.2, out.2012. Disponível em: www.nucleus.feituverava.com.br > Capa > v. 9, n. 2 (2012). Acessado em: 15/03/2014. 